\title{
DIÁLOGOS COM O CAVALEIRO INEXISTENTE: O ENSINO DE HISTÓRIA ENQUANTO CAMPO DE PESQUISA
}

\author{
NO SUCH DIALOGUES WITH THE KNIGHT: THE TEACHING OF \\ HISTORY AS A FIELD OF SEARCH
}

André Victor Cavalcanti Seal da Cunha ${ }^{1}$

\begin{abstract}
RESUMO: Neste artigo realizo reflexões acerca da especificidade do ensino de História enquanto campo de pesquisa. Considero que pelo "entre" lugares que ocupa a condição sine qua non de qualquer investigação no campo do ensino de História é necessariamente um intenso diálogo com a História e com a Educação. Contudo, as áreas de vinculações e referências para o ensino de História não se encerram aqui. Também as Ciências Sociais, a Filosofia, a Psicologia Cognitiva, a Geografia, a Lingüística, a Literatura, a Comunicação, as Artes, dentre outras, fornecem chaves de leitura aos fenômenos que pesquisamos. É, portanto, a miscelânea, a mestiçagem que permite o estabelecimento de pontes, o aflorar da criatividade, as potencialidade de inteligibilidade, compreensão, emancipação. Ao observar os trabalhos do campo, percebe-se que há um fio condutor, uma perspectiva integradora, uma unidade na diversidade, se entendermos a Didática da História como uma disciplina que investiga os processos circulação e ensino-aprendizagem da História no mundo da cultura, envolvendo os mais diferentes níveis e modalidades da educação, incluindo se o ensino superior e os espaços não escolares. Vemos assim que o campo do ensino de História no Brasil dá mostras de que há uma didática da história com o entrelaçamento de diferentes matrizes teóricas. Penso, portanto, que a vinculação da didática da História é com o campo do ensino de História, o que permite articulação nas análises tanto com a teoria da história quanto com a psicologia cognitiva ou a didática geral.
\end{abstract}

Palavras-chave: Ensino de História. Didática da História. Epistemologia do Ensino de História.

\footnotetext{
${ }^{1}$ Formado em História pela UFPE, possui mestrado em Educação pela mesma instituição. Professor de Metodologia do Ensino de História na Universidade do Estado do Rio Grande do Norte (UERN), atualmente é doutorando do Programa de Pós-Graduação em História da UFC.
} 


\begin{abstract}
This paper presents reflections on the specificity of teaching history as a field of research. I believe that the "between" places it occupies, the sine qua non of any research in the field of teaching history is necessarily an intense dialogue with the history and education. However, the areas of linkages and referrals to the teaching of history do not end here. Also, the Social Sciences, Philosophy, Cognitive Psychology, Geography, Linguistics, Literature, Communication Arts, among others, provide keys to understanding the phenomena that we investigate. It is therefore a hodgepodge, a mixture that allows the establishment of bridges, the flourishing of creativity, the capability of understanding, understanding and empowerment. By observing the work of the field, one realizes that there is a thread, an integrative approach, a unity in diversity, if we understand the history didactics as a discipline that investigates the processes of movement and teaching and learning of history in the world of culture, involving many different levels and types of education including the higher education and non-schooling. Thus we see that the field of teaching history in Brazil is showing that there is a teaching of history with the intermingling of different theoretical frameworks. I therefore think that the linking of teaching of history is with the field of teaching history, which allows linkage analysis in both the history and theory with cognitive cognitive psychology or teaching general.
\end{abstract}

Keywords: History teaching. Didactics of History. Epistemology of Teaching History.

Escrevo no convento, deduzindo coisas de velhos documentos, de conversas ouvidas no parlatório e de alguns raros testemunhos de gente que por lá andou. (CALVINO, 2005, p. 31)

Com essa descrição do seu trabalho de escrita, irmã Teodora, narradora ficcional criada por Ítalo Calvino, procurou legitimar, trazer autoridade, a história contada por ela. Trata-se dos feitos de Agilulfo, o Cavaleiro Inexistente. Inexistente porque diferentemente dos outros homens portadores de corpos de carne e osso, Agilulfo não tem existência física concreta dissociada de sua armadura. Aos olhares dos outros mortais, o que há é apenas uma armadura brilhante, preenchida pelo vazio, pelo nada.

Esse personagem, na obra que recebeu seu nome - O Cavaleiro Inexistente - me parece materializar um tipo de racionalidade muito presente no modo como fazemos ciência e conduzimos nossas 
investigações. Um trecho do livro em especial projeta luz em minha afirmativa. Nele, o jovem Rambalo, pergunta como tornar-se um paladino:

Agilulfo, antes de virar-se para ele, permaneceu um momento de costas, como se sublinhasse sua irritação em ser interrompido no cumprimento de uma missão; depois, já de frente, começou um discurso solto e enxuto, no qual se captava o prazer de apropriar-se rapidamente de um tema que lhe era proposto no momento e tratá-lo de modo competente.

- Segundo me diz, aspirante a cavaleiro, parece considerar que nossa condição de paladinos implique exclusivamente cobrir-se de glórias, seja em combate no campo das tropas, seja em audazes empresas individuais, entendo estas últimas tanto como defender nossa santa fé quanto socorrer mulheres, velhos, enfermos. Entendi bem?

- Sim.

- Pronto: com efeito, o que enumerou são todas as atividades inerentes ao nosso corpo de oficiais escolhidos, mas... - e aqui Agilulfo soltou uma risadinha, a primeira que Rambalo ouvia daquele gorjal branco: era um risinho cortês e sarcástico ao mesmo tempo - ...mas não as únicas. Se quiser, para mim é fácil enumerar uma por uma as tarefas que competem aos paladinos simples, aos paladinos de primeira classe, aos paladinos do estado-maior. (CALVINO, 2005, p.45)

Calvino explicita aqui a lógica hierarquizante e classificatória que norteia o cavaleiro inexistente. Lembrei imediatamente de Agilulfo ao ler o artigo publicado na RBH sob o título "Para uma Definição de Didática da História" de Oldimar Cardoso². Dedicarei grande parte deste trabalho ao diálogo com esse autor. Seu artigo vem suscitando reflexões e debates em diversos espaços acadêmicos. O esforço da análise que se segue possui como pressuposto o reconhecimento de sua contribuição. Apesar da convergência apenas parcial com seu pensamento e dos pontos de distanciamento, o exercício da crítica por si só revela o valor ou importância da produção. Vislumbrar, portanto, um campo de investigação denominado de didática da História de forma diferente da proposta por Cardoso não significa participar da dinâmica da exclusão, produtora de vazio e sombras (SERRES, 1999, p. 45) Diálogo exige abertura e humildade epistemológica. Tendo a concordar com Serres: "Jamais compreendi por que é preciso

2 Cardoso, Oldimar. Para uma Definição de Didática da História In: Revista Brasileira de História. São Paulo, v. 28, no 55, p. 153-170 - 2008 
romper, como você diz, com aqueles que não partilham uma mesma maneira de ver" (SERRES, 1999, p. 44)

\section{Uma Definição de Didática da História}

Em seu texto, Cardoso propõe uma concepção de Didática da História enquanto uma subárea da História, sendo a primeira uma disciplina subordinada ao campo da teoria da História. Segundo o autor, a bibliografia alemã que dá sustentação à sua proposição a consideraria mais próxima da História do que da educação. As investigações, realizadas com o recorte epistemológico desta nova disciplina, foram denominadas por Cardoso de pesquisas didáticohistóricas. Diferenciar-se-iam das pesquisas educacionais que tratam do ensino da História porque não se limitariam "ao contexto institucional da educação básica nem propõem compreendê-lo isolado da cultura e da consciência históricas externas a ele" (CARDOSO, 2008, p.166). Ainda segundo o autor, as pesquisas educacionais com enfoque nas práticas de ensino de História abstrairiam das análises das aulas "os conteúdos nelas tratados" (CARDOSO, 2008, p. 163), já as pesquisas desta nova disciplina denominada por Cardoso de Didática da História "sempre se submete ao pressuposto de entender forma e conteúdo da aula como um todo inseparável" (Ibidem). Assim, conclui Cardoso, "[...] essa área de estudo não é pedagógica, mas histórica, ao contrário das representações mais comuns sobre ela no Brasil" (CARDOSO, 2008, p. 166).

Apesar de, em diversas passagens, como nesta última afirmativa, haver uma falta de clareza nas afirmações, o que gera certa confusão de entendimento sobre o que está propondo Cardoso, o autor não defende a área do ensino de História como sendo exclusivamente ligada à História, mas com seu artigo pretende fundar um campo disciplinar a partir de uma 
matriz alemã. É neste sentido que a didática da História estaria para a História escolar como a teoria da História está para a História dos Historiadores (CARDOSO, 2008, p. 158). Vemos assim que a proposta do autor é transformar a abordagem alemã em campo de conhecimento no Brasil, transplantando uma lógica disciplinar que faz sentido na Alemanha, mas, como veremos adiante, que não corresponde às múltiplas referências do percurso histórico de constituição do campo do ensino de História e de uma didática da História no caso brasileiro.

Para fundamentar sua (pro)posição Cardoso realiza uma série de operações, articulando, segundo ele, bibliografias da Alemanha, da França e do Brasil. Realizarei aqui análises de algumas afirmativas que me pareceram descontextualizadas ou inapropriadas. Vejamos o parágrafo de abertura do texto:

No Brasil a Didática da História é freqüentemente entendida como um tema subordinado à área de Educação, sem vínculos com a atuação do pesquisador da área de História. Essa concepção se fundamenta na crença de que o papel da didática é adaptar ao contexto escolar o conhecimento criado pelos historiadores. (CARDOSO, 2008, p.154).

Sinto dificuldades em caminhar com essa compreensão. No caso brasileiro, ainda não é usual a utilização da categoria "Didática da História" para aglutinar pesquisas em um determinado campo de conhecimento acadêmico. É facilmente demonstrável que a categoria central no Brasil é "Ensino de História". Considero o uso da noção de subordinação pouco interessante, porém bastante eloqüente, reveladora até, das concepções epistemológicas que norteiam a posição de Cardoso. Como discutirei mais adiante, em um território híbrido, mestiço no dizer de Serres (1999), podemos falar em vinculações, referências preponderantes, apropriações, mas não em subordinação a uma determinada área.

Quanto à desvinculação de pesquisadores da área de História nas pesquisas sobre o ensino da disciplina, gostaria de refletir mais detidamente. Considero imprescindível distinguirmos a área de conhecimento acadêmico dos programas de pós-graduação que formam 
seus pesquisadores. Inegavelmente a formação dos pesquisadores do ensino de História vem se dando em sua maioria nos programas de PósGraduação em Educação, como é o caso inclusive do próprio Cardoso. Apesar disto, várias de nossas referências tiveram a formação em programas de Pós-Graduação em História, a exemplo de Circe Bittencourt, Antônia Terra, Margarida Oliveira, Carolina Galzerani, Thaís Fonseca, dentre outras autoras e outros autores. Entretanto, sem dúvida, o pesquisador do ensino de História ainda representa um Outsider (ELIAS, 2000). O problema consiste no fato de que a maioria dos programas de História não reconhece o ensino de História como objeto de pesquisas ou trata-o, quando muito, como um objeto menor. Não obstante, esta realidade vem modificando-se com a inserção de linhas de pesquisa em ensino de História nos programas de História - a exemplo dos programas da UFPB e da UEL - e o acolhimento de projetos relacionados ao ensino nas linhas já existentes. Agora o que é preciso inquirir é se os pesquisadores com formação em programas de pósgraduação em Educação não integram a área da História, o que fazem estes apresentando suas investigações nos simpósios nacionais da ANPUH ou publicando seus textos na Revista Brasileira de História, contando inclusive com volumes específicos? Considero que a característica híbrida do nosso campo de estudos permite a formação nos dois programas, pois um pesquisador do ensino de História é necessariamente um anfíbio.

Outra questão relevante a ser apontada é a articulação implícita da compreensão da Didática enquanto conhecimento relacionado à facilitação da aprendizagem de conhecimentos escolares, em nosso caso, históricos escolares. Como afirmar que essa concepção fundamenta uma didática da História no Brasil? Estaríamos tratando com o senso comum pedagógico ou com um campo de investigações acadêmicas, com uma subárea da educação? Apenas no senso comum a concepção de didática permanece relacionada a uma facilitação do ensino. É neste sentido que nossos alunos afirmam que tal professor tem uma boa didática. Mas no campo acadêmico a didática representa uma subárea da educação, contando com um objeto próprio: os processos educacionais nas quais se estabelecem uma relação entre professores, alunos e um saber (CORDEIRO, 2007, p. 20). Como 
demonstra Ventorim (2005), em sua análise da produção científica dos Encontros Nacionais de Didática e Práticas de Ensino (ENDIPEs), de 1994 a 2000 ocorreu uma consolidação da ampliação significativa dos objetos de estudo, englobando diferentes níveis, modalidades e espaços não-escolares. Vemos assim que é inapropriado não reconhecer a didática como campo acadêmico, ignorando as pesquisas que desde a década de 1980 abandonaram esta concepção instrumentalizante da disciplina.

Um aspecto que gostaria de problematizar refere-se às proposições de ordem teórico-metodológicas de Cardoso quando este busca caracterizar as pesquisas denominadas por ele de Didático-Históricas. Analisemos algumas delas.

O estranhamento não é uma condição de êxito de pesquisas de campo didático-históricas porque as diferentes experiências e vivências profissionais do pesquisador na área da cultura histórica não são obstáculos à análise do contexto de campo. Pelo contrário, essas experiências e vivências são um elemento indispensável à realização da pesquisa enquanto auto-reflexão. A familiaridade do pesquisador com a cultura histórica não é um problema, mas a condição sine qua non da pesquisa didático-histórica. É somente o confronto das experiências e vivências do pesquisador com as do contexto de campo que possibilita a auto-reflexão sobre a cultura histórica. As experiências e vivências do pesquisador não são, portanto, uma parte da sua subjetividade que precisaria ser eliminada. Em vez de eliminá-la, ele precisa explicitá-la aos atores de campo e adquirir consciência dela, com o intuito de administrá-la. (CARDOSO, 2008, p. 164)

A noção de "estranhamento" foi apropriada pelo autor aproximando-a de "distanciamento". Há aqui uma certa confusão conceitual. Abordagens que defendem uma aproximação, familiarização ou mesmo imersão no contexto de campo consolidaram-se nas Ciências Sociais, na Educação e na História desde a década de 1980, representando esta perspectiva um consenso amplamente consolidado nas pesquisas qualitativas que analisam práticas pedagógicas. No que tange ao estranhamento como recurso epistemológico, este me parece não representar uma tomada de distância do objeto em estudo, mas uma abertura para a dúvida, para o 
questionamento das próprias crenças, para se permitir desconfiar do óbvio. Um distanciamento crítico está marcado por um duplo movimento: o desfamiliarizar um presente que tendemos a ter como normal e nos familiarizar com um passado cuja fisionomia cotidiana nos foge (GINZBURG, 2007, p. 153). Desta forma, não vejo como caracterizar a abordagem defendida por Cardoso como uma especificidade metodológica das pesquisas auto-denominadas de didático-históricas.

Ainda sobre as proposições metodológicas, uma determinada passagem me causou inquietação.

Para dar um exemplo concreto, a tentativa de separar observação de interpretação ocorre quando o pesquisador registra que o professor afirmou que os populistas eram 'demagogos' - e ao final da aula pergunta para o professor o que exatamente essa palavra significa para ele naquele contexto -, em vez de registrar que o professor criticou o populismo. O objetivo de tal tentativa de separação é garantir que a retomada do material elaborado e coletado pelo pesquisador em campo permita atribuir aos gestos um sentido diferente daquele que seria atribuído no 'calor' do campo. Se o pesquisador registra que o professor criticou o populismo, não há a oportunidade de reinterpretar sua declaração de uma forma mais refletida. Buscar separar observação de interpretação significa evitar juízos de valor muito rígidos em campo, para conferir um papel importante à reflexão efetuada fora dele. Em outros casos, mais complexos do que esse exemplo, a separação é impossível. Então, observação e interpretação fundem-se em campo de forma indistinguível. Por isso, o esforço para distinguir observação e interpretação não garante nenhuma objetividade à interpretação do pesquisador, mas expressa sua responsabilidade de aproximar-se constantemente de seu objeto.

Tal responsabilidade é necessária para evitar que a pesquisa de campo didático-histórica fique refém da autoridade do pesquisador e permitir que assuma como critérios de validade a apresentação de 'provas' e a adequação de suas afirmações ao real. (CARDOSO, 2005, p. 165).

A longa citação justifica-se pela relevância. Ela me causou preocupação pelas possíveis implicações para as pesquisas no ensino de História. Cardoso aqui dispara sua crítica, se contrapondo a investigações que buscam analisar a metacognição dos docentes. Para os autores do paradigma "reflexivo" (GARCIA, 1995; MAROY, 2008; NÓVOA, 2008; PERRENOUD, 2001; TARDIF, 2008; ZEICHNER, 1993), os professores em 
sua prática pedagógica realizam um movimento de ação, reflexão na ação e reflexão da reflexão na ação. Esta última seria a metacognição, ou seja, a capacidade dos sujeitos de refletir sobre suas tomadas de decisão. O instrumento de coleta de informações sobre esta esfera na pesquisa qualitativa tem sido, de forma privilegiada, a entrevista aberta com questões elaboradas durante a observação das aulas e apresentadas aos docentes logo a seguir para que ele possa ter condições de acessar sua metacognição. Esse instrumento de coleta privilegiado vem sendo utilizado, por exemplo, no Instituto Nacional da Pesquisa em Pedagogia (IRNP) da Academia Francesa de Ciências ${ }^{3}$, cuja expoente principal de seu uso é Anne Marie Chartier. Foi com ele que essa autora, ancorada nas formulações de Michel de Certeau, diferenciou em suas investigações a coerência teórica dos acadêmicos da coerência pragmática dos professores, levando em consideração as representações e a lógica intrínseca dos sujeitos (1998; 2000 ; 2002). Neste sentido, a fase de análise dos dados é essencial para avançarmos na inteligibilidade dos fenômenos, para não ficarmos prisioneiros ao "calor" do campo. Uma abordagem que não leve em consideração as reflexões dos professores, que realize análises descritivas à luz de um marco teórico apropriado da teoria da História, utilizando-se de formulações elaboradas em outros contextos e definidas a priori, corre o risco de reatualizar discursos prescritivos e hierarquizantes sobre a prática pedagógica dos professores de História.

\section{Outra Percepção do Ensino de História: o que Nos Diz Michel Serres?}

Para dar continuidade ao nosso diálogo, sentimos a necessidade de trazer à baila outro autor. Filosofo e historiador da ciência, Michel Serres nos ajudou a sistematizar outra percepção do ensino de História enquanto

\footnotetext{
${ }^{3}$ Vale salientar que foi neste instituto que atuou André Chervel, autor amplamente utilizado por Cardoso em sua produção. Nele também Circe Bittencourt realizou pesquisas para o seu doutoramento.
} 
campo de investigação. Na obra intitulada "Atlas" Serres propõe uma alegoria ao estilo dos filósofos:

\begin{abstract}
Quando um nadador corajoso atravessa um rio largo ou um braço de mar amplo, o itinerário da sua viagem divide-se em três partes. Enquanto não perde de vista a margem de onde partiu ou avista a de chegada, habita ainda o seu ponto de origem ou já o alvo de seu desejo [...]. Ora, a meio do percurso, chega um momento decisivo em que, a igual distância das duas margens, durante a passagem mais ou menos longa de uma grande faixa neutra ou branca, ele não é ainda nem um nem outro e torna-se porventura já um e outro em simultâneo (SERRES, 1997, p. 24).
\end{abstract}

Serres complementa afirmando que a este espaço, misto, mestiço, da mistura de duas naturezas, fundido pelo encadeamento da transição, na língua francesa é designado pela proposição "entre" (SERRES, 1997, p. 2425). Penso que é exatamente essa a posição do ensino de História enquanto campo de pesquisa. Ocupando este "entre" lugares, está neste espaço do meio do caminho, tornando-se um e outro simultaneamente. Como quantificar ou definir uma maior ou menor proximidade a partir de um ponto de vista epistemológico? Falar em subordinação ao campo da História, da teoria da História ou da Educação seria revelar subserviência ao modelo de racionalidade científica ainda dominante, marcada pela lógica hierárquica, instrumental e estratégica (SERRES, 2008; SANTOS, 2001). Seria também negar a marca primordial deste campo híbrido: sua especificidade. Proponho assim uma outra percepção (no sentido proposto por Merleau-Ponty (2003) - e não definição, pois quando se define limita-se buscando controlar, reduzindo e submetendo o complexo - do ensino de História e da didática da História. A representação gráfica que se segue pode ajudar a metabolizar nossa compreensão. 


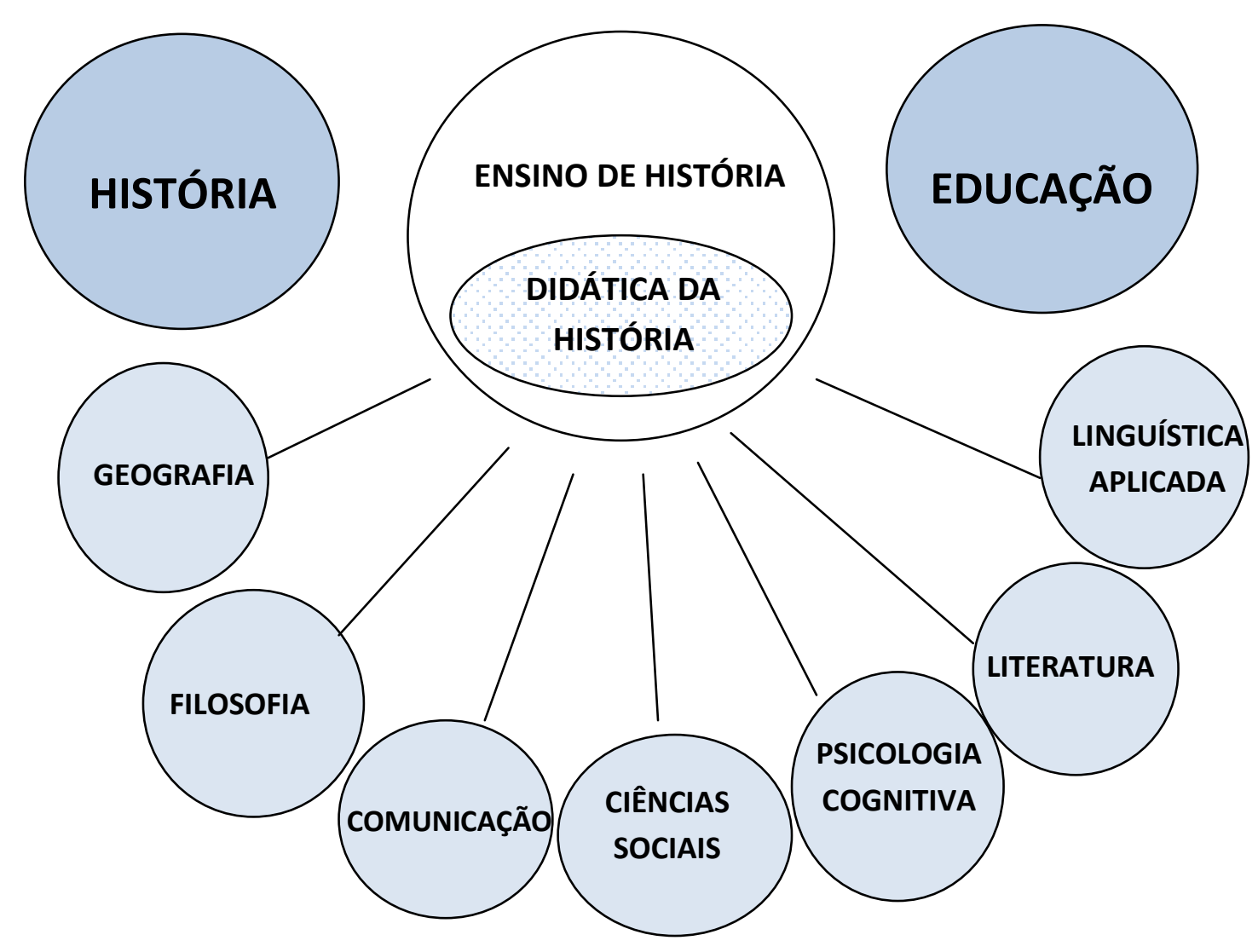

Pelo "entre" lugares que ocupa, a condição sine qua non de qualquer investigação no campo do ensino de História é necessariamente um intenso diálogo com a História e com a Educação, desempenhando papel essencial a teoria da História por fornecer arcabouço conceitual a ser apropriado para pensar a circulação de saberes históricos no mundo da cultura, sejam estes vinculados a espaços escolares ou não. Contudo, as áreas de vinculações e referências para o ensino de História não se encerram aqui. Também as Ciências Sociais, a Filosofia, a Psicologia Cognitiva, a Geografia, a Lingüística, a Literatura, a Comunicação, as Artes, dentre outras, fornecem chaves de leitura aos fenômenos que pesquisamos. Percebendo desta forma, como reduzir ou condicionar as pesquisas a um campo disciplinar exclusivo se é a miscelânea, a mestiçagem que permite o estabelecimento de pontes, o aflorar da criatividade, as potencialidade de inteligibilidade, 
compreensão, emancipação? Faço minhas as palavras de Roger Chartier (2002): é preciso seguir assim, "à beira da falésia". É nesta condição que o pesquisador do ensino de História caminha. Ele está à beira da falésia. Terá fatalmente que desfrutar das dores e delícias de sua posição. Sob os pés encontra-se próximo ao precipício, mas sua visão contempla novos horizontes.

\section{Para Pensar o Ensino de História por Dentro: Podemos Falar em uma Didática da História no Brasil?}

Para dar continuidade a nossas reflexões, verticalizando um pouco mais o nosso olhar, faz-se necessário pensar por dentro o campo do ensino de História. Vários trabalhos dão conta de um estado da arte sobre o ensino de História no Brasil. Nos referenciaremos aqui no que foi realizado por Ernesta Zamboni (2005, p. 37- 49). Segundo a autora, um recorte panorâmico no campo permite perceber que as investigações realizadas se caracterizam pela multidisciplinaridade e multirreferencialidade, pois nelas se entrecruzariam "diferentes saberes, diferentes áreas do conhecimento [...] (ZAMBONI, 2005, p. 37). Pelo painel apresentado, constata Zamboni que as pesquisas sobre o ensino de História consolidaram-se no Brasil durante a década de 1990. Há um significativo crescimento quantitativo e qualitativo das pesquisas e uma diversificação nas abordagens adotadas, com a constituição de subcampos. Desta forma, aglutinam-se investigações a partir de certas categorias centrais, tais como: a formação de professores de História, a História do ensino de História, o livro didático de História, o currículo de História, as práticas pedagógicas dos docentes da disciplina, a circulação de saberes históricos em espaço não escolares.

O que nos parece emergir quando nos debruçamos sobre o campo do ensino de História é o fato de que já existe um volume significativo de produções para caracterizar uma Didática da História. Ao observar os trabalhos, percebe-se que há um fio condutor, uma perspectiva integradora, uma unidade na diversidade, se entendermos a Didática 
da História como uma disciplina que investiga os processos circulação e ensino-aprendizagem da História no mundo da cultura, envolvendo os mais diferentes níveis e modalidades da educação, incluindo se o ensino superior e os espaços não escolares. É preciso então reconhecer que já existe uma Didática da História. Mesmo que não se percebam ou não se auto-denominem, muitos pesquisadores de nosso campo são didatas. Vemos assim que o campo do ensino de História no Brasil dá mostras de que há uma didática da história com o entrelaçamento de diferentes matrizes teóricas. Estas são apropriadas de forma hibrida, sem constituir ecletismos conceituais. Podemos falar no caso brasileiro em didática da História sem vinculá-la a uma matriz específica ou exclusiva. Penso, portanto, que a vinculação da didática da História é com o campo do ensino de História, o que permite articulação nas análises tanto com a teoria da história quanto com a psicologia cognitiva ou a didática geral. No mais, considero importante a superação de nosso complexo de vira-lata. Não há país europeu com uma comunidade tão expressiva de pesquisadores do ensino de História.

\section{Considerações Finais: Onde se Encaixa o Ensino de História?}

Talvez uma questão de fundo para as proposições de Cardoso seja como categorizar este "entre-lugar", chamado de "ensino de História", na atual taxionomia dos saberes acadêmicos. Em 2005 o Conselho Nacional de Desenvolvimento Científico e Tecnológico (CNPQ) disponibilizou para consulta pública sua nova tabela das áreas do conhecimento. Entre as novas especialidades listadas está a Educação Matemática, a Educação em Química e Ensino de Física (BRASIL, 2005, p. 21) Não existe referência ao ensino de História. Vivemos, portanto, uma situação paradoxal. Consolidado enquanto campo de pesquisa, o ensino de História não é reconhecido ou legitimado pela agência regulatória do campo científico mais importante do país. Não por acaso os ensinos das disciplinas das ditas ciências duras 
contam com programas de pós-graduação específicos, vinculados tanto a centros de educação como a departamentos das disciplinas de referência ${ }^{4}$.

Diante desta composição de força, do quadro de disputas disciplinares por espaço e lugar ao sol, considero que a questão da vinculação a áreas não é estritamente epistemológica, mas em grande medida política, como não poderia deixar de ser. Considero assim a atuação de Cardoso como uma tentativa corajosa de se posicionar no debate para recompor a trama na qual estamos inseridos. No entanto, ao defender posições que soam como hierarquizantes ${ }^{5}$, arisca-se a retomar em novas bases análises da prática pedagógica dos professores de História que não levavam em consideração a lógica dos sujeitos. Muito esforço teórico foi realizado para incorporar a perspectiva dos atores, dos usuários, dos consumidores, para usar uma expressão de Certeau (2004).

Acredito que ao buscar fundar uma disciplina ele não foi levado pela arrogância cósmica tão comum na galáxia acadêmica. Não é uma questão de soberba intelectual, mas de formação. Cardoso é Agilulfo. Segue o modelo de racionalidade disciplinar dominante na ciência moderna. Usa suas melhores energias para constituir um campo, erguer uma categoria. Mas corre os mesmos riscos do cavaleiro inexistente e pode padecer do mesmo destino. Como Agilulfo, sua proposta, ao final, pode dissolver-se no ar.

\section{Referências}

CALVINO, I. O Cavaleiro inexistente. São Paulo: Companhia de Bolso, 2005.

CARDOSO, O. Para uma definição de Didática da História. Revista Brasileira de História, São Paulo, v. 28, n. 55, p. 153-170, 2008.

CERTEAU, M. A invenção do cotidiano. 10.ed. Petrópolis: Vozes, 2004.

\footnotetext{
${ }^{4}$ Este por exemplo é o caso dos Programas de Pós-Graduação em Educação Matemática.

${ }^{5}$ Explicitadas na utilização de noções como "subordinação" a teoria da História ou "História sem forma científica". Vale salientar que com relação a esta última, na atual conjuntura não nos cabe mais a ingenuidade de pensar que ao definir tipos de Histórias como sendo com ou sem forma científica não estaríamos contribuído para a perpetuação de relações de poder hierárquicas e verticais entre o campo acadêmico e o campo escolar.
} 
CHARTIER, A-M. L. L'expertise enseignante entre savoirs practiques et saviors théoriques. Recherche et Formation. Les savoirs de la pratique: um enjeu por la recherche et la formation. INRP, n. 27, p. 67-82, 1998.

CHARTIER, R. Fazeres ordinários da classe: uma aposta para a pesquisa e para a formação. Educação e Pesquisa, São Paulo, v. 26, n. 2, p. 157-168, jul./dez. 2000.

Sucesso, fracasso e ambivalência da inovação pedagógica: o caso do ensino de leitura. Conferência proferida no Centro de Educação - UFPE, 2002.

À beira da falésia: a história entre certezas e inquietudes. Porto Alegre: Ed. UFRGS, 2002.

CORDEIRO, J. Didática. São Paulo: contexto, 2007.

ELIAS, N.; SCOTSON, J. Os estabelecidos e os outsides. Rio de Janeiro: Jorge Zahar Editor, 2000.

GARCIA, C. M. A formação de professores: novas perspectivas baseadas na investigação sobre o pensamento do professor. In NÓVOA, A. (Org.). Os professores e sua formação. Lisboa: Dom Quixote, 1995.

GINZBURG, C. O fio e os rastros: verdadeiro, falso, fictício. São Paulo: Companhia das Letras: 2007.

MAROY, C. O modelo do prático reflexivo diante da enquete na Bélgica. In TARDIF, M. e LESSARD, C. (Org.). O ofício de professor: história, perspectivas e desafios internacionais. Petrópolis: Vozes, 2008.

MERLEAU-PONTY, M. Palestras. Lisboa: Edições Setenta, 2003.

NÓVOA, A. Os professores e o 'novo' espaço público da educação. In TARDIF, M. e LESSARD, C. (Org.) O ofício de professor: história, perspectivas e desafios internacionais. Petrópolis: Vozes, 2008.

PERRENOUD, P. Ensinar: agir na urgência, decidir na incerteza. 2.ed. Porto Alegre: Artmed, 2001.

SANTOS, B. de S. Um discurso sobre as ciências. 12.ed. Porto: Afrontamentos, 2001.

SERRES, M. Atlas. Lisboa: Instituto Piaget, 1997.

1999. Luzes: cinco entrevistas com Bruno Latour. São Paulo: UNIMARCO, Ramos. Rio de Janeiro: Bertrand Brasil, 2008. 
TARDIF, M.; LESSARD, C. (Org.). O ofício de professor: história, perspectivas e desafios internacionais. Petrópolis: Vozes, 2008.

ZAMBONI, E. Encontros nacionais de Pesquisadores de História: Perspectivas. In ARIAS NETO, J. M. (Org). Dez anos de pesquisas em ensino de História. Londrina: AtritoArt, 2005.

ZEICHNER, K. A formação reflexiva de professores: idéias e práticas. Lisboa: EDUCA, 1993. 